\title{
Irregularly shaped small shadows on chest radiographs, dust exposure, and lung function in coalworkers' pneumoconiosis
}

\author{
H P R COLLINS, ${ }^{1}$ J A DICK, ${ }^{2}$ J G BENNETT, ${ }^{2}$ P O PERN, ${ }^{2}$ M A RICKARDS, ${ }^{2}$

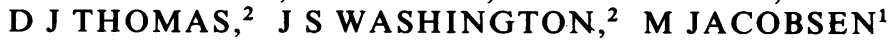

From the Institute of Occupational Medicine, ${ }^{1}$ Edinburgh EH8 9SU, and British Coal Radiological Services, ${ }^{2}$ London $S W I X 7 A E, U K$

ABSTRACT The predominant shapes of small opacities on the chest radiographs of 895 British coalminers have been studied. The aims were to determine whether irregular (as distinct from rounded) small opacities can be identified reproducibly, whether their occurrence is related to dust exposure, and whether they are associated with excess prevalence of respiratory symptoms or impairments of lung function. Six of the doctors responsible for regular radiological surveys of all British coalminers each classified all 895 radiographs twice and independently, using the International Labour Organisation's 1980 classification system. The majority view was that 39 films showed predominantly irregular small opacities, 131 showed predominantly small rounded opacities, and 587 showed no small opacities. Readers' opinions varied about the presence and shapes of shadows on the other 138 films. In general, consistency between readers (and within readers on repeated viewings) was satisfactory. The occurrence and profusion of irregular shadows were related significantly both to the men's ages and additionally to their cumulative exposure to respirable coalmine dust as determined from 15 years' dust monitoring close to where the miners had worked. For any given level of exposure, the average level of profusion of the small irregular opacities was less than the corresponding profusion of small rounded opacities. The prevalence rates of chronic cough and phlegm, and of breathlessness, were higher in those with small irregular opacities than in those with no small opacities (category $0 / 0$ ), but the differences were not statistically significant after adjustment for other factors including smoking habits. The presence of irregular (but not rounded) small shadows was associated with an impairment in respiratory function averaging about $190 \mathrm{ml}$ deficits in both $\mathrm{FEV}_{1}$ and FVC. These deficits were not explicable in terms of the men's ages, body sizes, and smoking habits and they were in addition to the lung function losses attributable to the miners' dust exposure as such. It is concluded that the presence and profusion of small irregular opacities should be taken into consideration when assessing the severity of coalworkers' simple pneumoconiosis.

The International Labour Organisation's (ILO) classification of the chest radiographic appearances of pneumoconiosis distinguishes between small opacities that are rounded in shape and those that are irregular. ${ }^{1}$ Present estimates of the risk of coalworkers' simple pneumoconiosis in relation to respirable dust exposure are based on studies in which the criterion for pneumoconiosis has been the presence of small rounded opacities; irregular opacities were not considered specifically. ${ }^{23}$ Small irregular opacities, how-

Accepted 9 March 1987 ever, also occur on the chest radiographs of coalminers, ${ }^{4}$ and the frequency of their occurrence has been related to years worked underground, ${ }^{56}$ suggesting that they, in addition to rounded opacities, might result from dust exposure. Irregular opacities may also have different clinical implications from those of rounded opacities, in that the former have been related to reduced lung function ${ }^{67}$ and to pathological evidence of emphysema and interstitial fibrosis. ${ }^{8}$

A preliminary report of a more recent study has confirmed that small irregular opacities are indeed 
related to dust exposures when the exposure estimates are based on detailed measurements of respirable dust concentrations and occupational records. ${ }^{9}$ We now report further on those results from 895 British coalminers. The differences between small irregular and rounded opacities in their relation with dust exposure are quantified, and the occurrence of respiratory symptoms and lung function levels in men whose radiographs show the differently shaped small shadows are compared.

\section{Materials and methods}

The chest radiographs included in this study were from 900 men sampled from a population of 3600 miners who attended the first four of a series of quinquennial surveys at 10 British coalmines included in a longitudinal project known as the Pneumoconiosis Field Research. ${ }^{2}$ This ensured that the full sized (posteroanterior) chest radiographs had been obtained by standardised methods and also that estimates of cumulative (working life) exposures to dust for the individuals concerned were available based on 15 years' systematic monitoring of dust concentrations close to where the miners had worked. ${ }^{3}$ The sample of men was stratified to give an approximately uniform distribution of dust exposures and ages over all possible ranges. ${ }^{9}$ The radiographs were from the fourth round of medical surveye that took place between March 1970 and November 1973.

As five radiographs were unavailable at time of reading, 895 were examined twice by each of six of us according to the ILO 1980 Classification of Radiographs of Pneumoconioses. ${ }^{1}$ This determined that the profusion of any small opacities consistent with pneumoconiosis, irrespective of their shape, was categorised on an ordinal scale and that the shapes (and sizes) of those opacities were recorded subsequently in a way that identified the predominant shapes as rounded or irregular. We examined the radiographs independently and in different random orders on both occasions.

For the analysis, the films were grouped subsequently as follows. A film was categorised as showing one or other predominant shape of opacities or the absence of small opacities (category $0 / 0$ ), at either one of the two readings, if more than three readers agreed about the predominant shape, or absence of opacities, at that reading. Similar allocations were made if three readers agreed and the other three were not unanimous in nominating the alternative predominant shape (or absence of small shadows). This provided four mutually exclusive groupings of films from each of the two sets of six readings: those judged as showing predominantly rounded small opacities, predominantly irregular small opacities, no small opac- ities (category 0/0), and those where there was insufficient agreement between readers to permit allocation to any of the above according to the conventions defined.

Average profusion scores were calculated for each radiograph based on classifications by all six readers on both occasions. The profusion scale defining the scores ranged from 0 to 10 , representing categories $0 / 0$ to $3 /+$. (No recordings of category $0 /-$ were made.)

Questionnaires about respiratory symptoms and smoking habits had been administered at survey ${ }^{10}$ and lung function had been measured by simple spirometry. ${ }^{11}$ The questionnaire responses were used to classify men into four smoking categories: current cigarette smokers, current "other" smokers consisting of pipe and cigar smokers, ex-smokers, and lifelong non-smokers. Some smoking histories for those who said at fourth survey that they were cigarette smokers, and for those who said that they had never smoked, were inconsistent with their replies to questionnaires administered at two earlier surveys. Therefore, using smoking data from the second, third, and fourth surveys, we reclassified those individuals as follows: 26 fourth survey cigarette smokers were reclassified as "other" smokers and 15 nominal non-smokers were reclassified as ex-smokers. This provided sets of consistent responses about cigarette smoking and nonsmoking, where the cigarette smokers had smoked for at least 10 years before the survey.

From the answers to the questionnaire at fourth survey, the combination of cough and phlegm, both for more than three months in the year, was defined as chronic cough and phlegm. Men who answered positively to the question: "Do you have to walk more slowly than other people on level ground because of your chest?" were regarded as suffering from breathlessness. Men who reported either or both of these symptoms were classified into two mutually exclusive groups: (a) those with chronic cough and phlegm but no breathlessness and (b) those with breathlessness. (Some but not all in group (b) also reported cough and phlegm.)

Records of individuals' exposures to respirable mine dust during the approximately 15 year periods from the start of the research were complete. In each case there was available also information obtained at interview about occupational history before the initial survey and this was used to estimate the earlier exposures to dust. The exposure units are grams of respirable dust per cubic metre of sampled air multiplied by hours of exposure $\left(\mathrm{ghm}^{-3}\right)$. A $200 \mathrm{ghm}^{-3}$ exposure (the mean of those contributing to the analyses reported here) if accumulated over, say, 30 working years before 1970 would imply that the miner concerned had worked at places where the time averaged 
concentrations of respirable dust were about $3.8 \mathrm{mgm}^{-3}$. Further details of how these exposures were derived have been recorded elsewhere. ${ }^{3}$

Statistical methods used in the analysis of the results appealed to the logit transformation of quantal response variables (occurrences of small opacities and of respiratory symptoms) with the effects of explanatory variables estimated by maximum likelihood and multiple regression representations of the lung function data fitted by least squares. In both cases the Genstat computer package was used. ${ }^{12}$

\section{Results}

VARIABILITY IN RADIOLOGICAL ASSESSMENTS The aggregates of the six readers' distributions of classifications into the 12 ILO small opacity profusion categories were similar on the two occasions when the films were classified. The proportion of films judged as showing any small opacities (category $0 / 1$ or higher on the scale) averaged $32 \%$ over all 12 sets of classifications and varied between readers from $16 \%$ to $44 \%$. Consistency within readers in their duplicate profusion classifications of the same films ranged from $65 \%$ identical classifications (from three of the readers) to $84 \%$ from the most consistent reader.

Consistency in readers' judgments about the predominant shape of any small opacities that they saw varied from $69 \%$ identical judgments about predominant shape on 341 films classified as showing some small opacities by one reader to $90 \%$ of 100 such films that were thus identified by another reader. Agreement between pairs of readers about the predominant shape (rounded or irregular) of small opacities on films that both classified as category $0 / 1$ or higher ranged from $62 \%$ to $89 \%$ and averaged $76 \%$.

Further details of variability between and within readers are described elsewhere. ${ }^{9}$ Table 1 now summarises the degree of concordance between majority views at first and second readings regarding predominant shape of small opacities. One hundred and thirty one radiographs were classifiable as showing predominantly small rounded opacities at both readings, 39 were classifiable as showing predominantly small irregular opacities, and the majority view was that 587 of the films had no small opacities. This grouping of the films leaves 138 where the degree of agreement about their appearances at either or both readings did not meet the criteria defined.

Table 2 shows the extent to which individual classifications of the films support their inclusion in these four mutually exclusive groups. The assumption that there were virtually no small opacities on 587 of the films seems most secure; only $8 \%$ of the 7024 classifications nominated any small shadows. The concensus about predominantly small rounded shapes on 131 films is based on $85 \%$ of 1568 classifications, whereas the 39 films characterised as showing predominantly irregular shapes attracted 320 such classifications, representing $68 \%$ of the total available. A further $52(11 \%)$ of the 468 classifications of the latter 39 films nominated some irregular shadows in the presence of predominantly rounded shapes. In both groups of films characterised by concensus as showing some small shadows more than half of the available classifications reported only one shape, rounded or irregular, with no mention of the alternative shape.

Clearly the presence or shapes of small opacities on the remaining 138 films cannot be determined reliably from these readings. The analyses reported below are therefore restricted to the other three sets of radiographs, representing $84 \%$ of the miners studied. References to one or other predominant shape of small shadows will refer to the majority view as defined by table 2 .

Table 1 Distribution of majority categorisations* of the appearances of 895 chest radiographs by six readers on repeated and independent viewings. (Analyses with respect to dust exposure, respiratory symptoms, and lung function reported in this paper are confined to the 757 films framed in the main diagonal of the table)

\begin{tabular}{|c|c|c|c|c|c|}
\hline \multirow[b]{2}{*}{ Second readings } & \multicolumn{2}{|c|}{ Predominant shapes of small opacities } & \multirow{2}{*}{$\begin{array}{l}\text { No small opacities } \\
\text { (Category 0/0) }\end{array}$} & \multirow{2}{*}{$\begin{array}{l}\text { Insufficient agreement } \\
\text { between readers }\end{array}$} & \multirow[b]{2}{*}{ Total } \\
\hline & Rounded & Irregular & & & \\
\hline \multirow{4}{*}{$\begin{array}{l}\text { First readings } \\
\text { Predominant shape } \\
\text { - Rounded } \\
\text { - Irregular } \\
\text { No small opacities (category } 0 / 0 \text { ) } \\
\text { Insufficient agreement }\end{array}$} & & & & & \\
\hline & 131 & $\frac{9}{30}$ & 8 & 10 & 158 \\
\hline & 4 & 39 & $\frac{12}{5877}$ & 14 & 69 \\
\hline & $\begin{array}{r}6 \\
13\end{array}$ & $\begin{array}{l}4 \\
7\end{array}$ & $\frac{587}{24}$ & $\begin{array}{l}13 \\
14\end{array}$ & $\begin{array}{r}610 \\
58\end{array}$ \\
\hline Total & 154 & 59 & 631 & 51 & 895 \\
\hline
\end{tabular}

${ }^{*}$ Variability of classifications between and within individual readers has been described previously. ${ }^{9}$ 
Table 2 Percentage distributions of shape classifications for films categorised on the basis of majority views at repeated viewings

\begin{tabular}{|c|c|c|c|c|}
\hline \multirow[b]{3}{*}{$\begin{array}{l}\text { No of films } \\
\text { No of classifications }\end{array}$} & \multicolumn{4}{|c|}{ Majority categorisation of predominant shape (from table 1) } \\
\hline & $\begin{array}{l}\text { Predominantly small } \\
\text { rounded opacities }\end{array}$ & $\begin{array}{l}\text { Predominantly small } \\
\text { irregular opacities }\end{array}$ & No small opacities & $\begin{array}{l}\text { Insufficient agreement } \\
\text { between readers }\end{array}$ \\
\hline & $\begin{array}{r}131 \\
1568\end{array}$ & $\begin{array}{r}39 \\
468\end{array}$ & $\begin{array}{r}587 \\
7024\end{array}$ & $\begin{array}{r}138 \\
1633\end{array}$ \\
\hline \multicolumn{5}{|c|}{ Percentage distribution of shape classifications } \\
\hline $\begin{array}{l}\text { Rounded only } \\
\text { Predominantly rounded with some irregular } \\
\text { Irregular only } \\
\text { Predominantly irregular with some rounded } \\
\text { No small opacities (category } 0 / 0 \text { ) }\end{array}$ & $\begin{array}{l}52 \cdot 6 \\
32 \cdot 3 \\
4 \cdot 7 * 1 \\
2 \cdot 2^{* 2} \\
8 \cdot 2\end{array}$ & $\begin{array}{l}3 \cdot 2^{* 3} \\
11 \cdot 1^{* 4} \\
57 \cdot 1 \\
11 \cdot 3 \\
17 \cdot 3\end{array}$ & $\begin{array}{r}2 \cdot 4 \\
1 \cdot 3 \\
4 \cdot 4 \\
0 \cdot 3 \\
91 \cdot 7\end{array}$ & $\begin{array}{r}12 \cdot 7 \\
14 \cdot 5 \\
27 \cdot 4 \\
6 \cdot 3 \\
39 \cdot 1\end{array}$ \\
\hline
\end{tabular}

*Notes on the number of films in selected subsets of classifications.

\begin{tabular}{|c|c|c|c|c|c|c|c|}
\hline \multirow[b]{2}{*}{ Subset } & \multirow[b]{2}{*}{ Classification } & \multirow{2}{*}{$\begin{array}{l}\text { Proportion } \\
\text { of all classifications }\end{array}$} & \multirow[b]{2}{*}{ No of films involved } & \multicolumn{4}{|c|}{$\begin{array}{l}\text { Distribution of these films } \\
\text { to number of classifications }\end{array}$} \\
\hline & & & & $I$ & 2 & 3 & 4 \\
\hline $\begin{array}{l}1 \\
2\end{array}$ & $\begin{array}{l}\text { Irregular only } \\
\text { Predominantly irregular with }\end{array}$ & $\begin{array}{l}74 / 1568=4 \cdot 7 \% \\
35 / 1568=2 \cdot 2 \%\end{array}$ & $\begin{array}{l}46 \\
30\end{array}$ & $\begin{array}{l}29 \\
27\end{array}$ & $\begin{array}{l}8 \\
1\end{array}$ & $\begin{array}{l}7 \\
2\end{array}$ & $\begin{array}{l}2 \\
0\end{array}$ \\
\hline $\begin{array}{l}3 \\
4\end{array}$ & $\begin{array}{l}\text { Rounded only } \\
\text { Predominantly rounded with } \\
\text { some irregular }\end{array}$ & $\begin{array}{l}15 / 468=3 \cdot 2 \% \\
52 / 468=11 \cdot 1 \%\end{array}$ & $\begin{array}{l}10 \\
25\end{array}$ & $\begin{array}{l}5 \\
7\end{array}$ & $\begin{array}{r}5 \\
10\end{array}$ & $\begin{array}{l}0 \\
7\end{array}$ & $\begin{array}{l}0 \\
1\end{array}$ \\
\hline
\end{tabular}

Table 3 Distribution of films with small opacities to profusion categories*

\begin{tabular}{lrrrrrrrrrr}
\hline \multicolumn{1}{c}{ Category } & & & & \\
\cline { 2 - 10 } & $0 / 1$ & $1 / 0$ & $1 / 1$ & $1 / 2$ & $2 / 1$ & $2 / 2$ & $2 / 3$ & $3 / 2$ & Total \\
\hline Predominantly small rounded opacities & 11 & 26 & 19 & 25 & 15 & 16 & 11 & 8 & 131 \\
Predominantly small irregular opacities & 4 & 20 & 8 & 5 & 1 & 1 & 0 & 0 & 39 \\
\hline
\end{tabular}

*Calculated from average profusion scores using integers to represent the ordered categories. (A random procedure was used to round up or down when the average score placed the film precisely on a boundary between categories.)

Table 4 Distribution of 757 miners' smoking habits according to the presence and shapes of small opacities, with corresponding means (and standard deviations) of respirable coalmine dust exposures ( $\mathrm{ghm}^{-3}$ )

\begin{tabular}{|c|c|c|c|c|c|}
\hline & \multicolumn{5}{|l|}{ Smoking habits } \\
\hline & Cigarette smokers & Other smokers & Ex-smokers & Non-smokers & All \\
\hline Predominantly small rounded opacities & $\begin{array}{l}68^{*} \\
327 \\
(136)\end{array}$ & $\begin{array}{c}15 \\
313 \\
(110)\end{array}$ & $\begin{array}{l}28 \\
297 \\
(119)\end{array}$ & $\begin{array}{c}20 \\
320 \\
(119)\end{array}$ & $\begin{array}{r}131 \\
318 \\
(126)\end{array}$ \\
\hline Predominantly small irregular opacities & $\begin{array}{c}25 \\
262 \\
(168)\end{array}$ & $\begin{array}{l}400 \\
(86)\end{array}$ & $\begin{array}{c}6 \\
298 \\
(139)\end{array}$ & $\begin{array}{c}4 \\
276 \\
(107)\end{array}$ & $\begin{array}{r}39 \\
283 \\
(153)\end{array}$ \\
\hline No small opacities (category $0 / 0$ ) & $\begin{array}{r}322 \\
\quad 167 \\
(100)\end{array}$ & $\begin{array}{l}73(75) \\
175 \\
(93)\end{array}$ & $\begin{array}{l}111 \\
172 \\
(111)\end{array}$ & $\begin{array}{c}81 \\
155 \\
(106)\end{array}$ & $\begin{array}{r}587 \\
167 \\
(102)\end{array}$ \\
\hline All & $\begin{array}{l}416 \\
200 \\
(127)\end{array}$ & $\begin{array}{l}92 \\
208 \\
(115)\end{array}$ & $\begin{array}{l}145 \\
201 \\
(125)\end{array}$ & $\begin{array}{l}105 \\
191 \\
(127)\end{array}$ & $\begin{array}{r}757 \\
199 \\
(125)\end{array}$ \\
\hline
\end{tabular}

*Each cell in the table shows: No of men in subgroup Mean dust exposure (SD) 


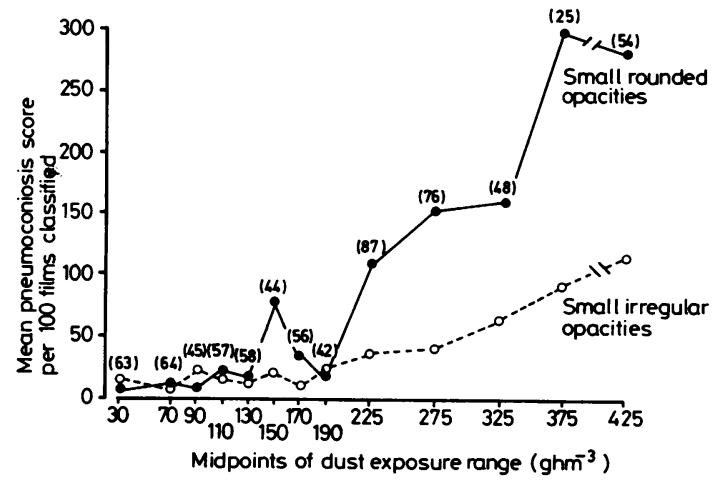

Fig 1 Averages of six readers' duplicate assessments of profusion of small opacities in subsets of 757 miners' chest radiographs. Mean pneumoconiosis scores are expressed as percentages of numbers of films on which they are based, so that 100 on the ordinate represents an average classification to category 0/1, 200 to category 1/0, etc. (Figures shown in parentheses are numbers of films contributing to calculations of mean profusions of small rounded opacities. They comprise all films categorised as showing no small opacities (587 in total) plus those with predominantly rounded opacities (131 films). Same convention was used to calculate mean scores for films showing predominantly small irregular opacities, so that number of films contributing to those means are $587+$ $39=626$ in total; see table 2.)

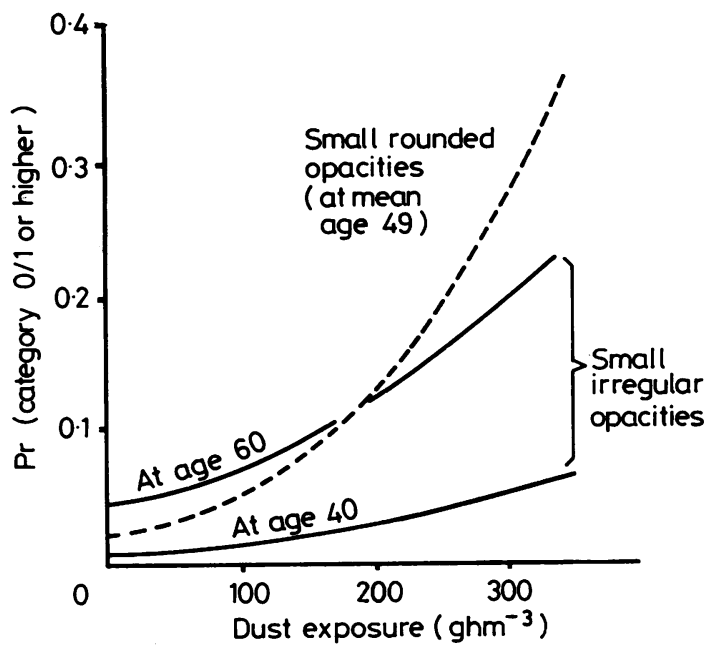

Fig 2 Estimates of probabilities* that cigarette smokers show some small opacities (category 0/1 or higher). ${ }^{*}$ Based on fitted logistic equations (see appendix). Those analyses showed no significant variations in probabilities depending on smoking habits and no significant effect of age for small rounded opacities.
SMALL OPACITIES AND DUST EXPOSURE

Films designated as showing predominantly small rounded opacities tended to attract higher profusion categories than those showing predominantly irregular shapes. The distributions to categories, based on average profusion scores, are compared in table 3. Only two $(5 \%)$ of the 39 films with predominantly irregular shadows had average scores meriting classification into category $2 / 1$ or higher on the scale. The 131 films with predominantly rounded small shadows included $42(32 \%)$ in ILO category 2 and eight $(6 \%)$ in category 3 .

Table 4 shows that both rounded and irregular opacities were associated with relatively high mean cumulative dust exposures in all smoking groups. Average pneumoconiosis scores for men classified as showing predominantly rounded or predominantly irregular opacities are shown plotted against the dust exposures in fig 1 . This confirms that the profusions of both types of opacity are related to dust exposure and that the rate of increase in the pneumoconiotic response with respect to exposure is more severe when only rounded shadows are considered. Figure 1 also illustrates the fairly uniform distribution of miners' dust exposures that was arranged for this study.

Details of analyses aimed at exploring the possible joint influences of age, dust exposure, and smoking habits on the chances of having either type of small opacity are recorded in the appendix. Neither age nor smoking habits contributed significantly to the risks of having small rounded opacities but there was a highly significant increase in those risks with increasing exposure to dust. This is illustrated in fig 2 for a cigarette smoker at the mean age (49).

Results from those who had predominantly irregular small opacities again showed no significant effect of variations in smoking habits. The estimated probabilities for a cigarette smoker and a non-smoker at the mean age and dust exposure $(6 \%$ and $4 \%$ respectively) were similar to the unadjusted proportions with small irregular opacities derivable from table 2 ( $7 \%$ and $5 \%$ respectively). The regresssion analysis, however, indicated that the chance of having small irregular opacities increased both with dust exposure and with age $(\mathrm{p}<0.003)$. The magnitudes of those effects are also illustrated in fig 2.

\section{RESPIRATORY SYMPTOMS AND SMALL}

OPACITIES

Table 5 shows that both chronic cough and phlegm (without breathlessness), and breathlessness irrespective of cough and phlegm, occurred more frequently in men with small radiographic shadows, irrespective of smoking habits, and that the associations were more pronounced in those who had small rounded opacities. 
Table 5 Percentages of men with (a) chronic cough and phlegm (without breathlessness), and (b) breathlessness (irrespective of cough and phlegm), in various subgroups. (Numbers in parentheses are the denominators used to calculate the percentages within the subgroups. They comprise the number of men with the relevant symptom, as defined, and the number with neither symptom.)

\begin{tabular}{|c|c|c|c|c|c|c|}
\hline & & \multicolumn{5}{|l|}{ Smoking habits } \\
\hline & & Cigarette smokers & Other smokers & Ex-smokers & Non-smokers & All \\
\hline (a) & $\begin{array}{l}\text { Chronic cough and phlegm: } \\
\text { Small rounded opacities } \\
\text { Small irregular opacities } \\
\text { No opacities (category 0/0) } \\
\text { Breathlessness: }\end{array}$ & $\begin{array}{l}56 \cdot 7(30) \\
46 \cdot 2(13) \\
36 \cdot 6(257)\end{array}$ & $\begin{array}{l}80 \cdot 0(5) \\
0(2) \\
19 \cdot 0(63)\end{array}$ & $\begin{array}{l}28 \cdot 6(14) \\
50 \cdot 0(4) \\
19 \cdot 3(88)\end{array}$ & $\begin{array}{l}33 \cdot 3(12) \\
50 \cdot 0(4) \\
9 \cdot 6(73)\end{array}$ & $\begin{array}{l}47 \cdot 5(61) \\
43 \cdot 5(23) \\
27 \cdot 0(481)\end{array}$ \\
\hline & $\begin{array}{l}\text { Small rounded opacities } \\
\text { Small irregular opacities } \\
\text { No opacities (category } 0 / 0 \text { ) }\end{array}$ & $\begin{array}{l}74 \cdot 5(51) \\
63 \cdot 2(19) \\
28 \cdot 9(228)\end{array}$ & $\begin{array}{l}90 \cdot 9(11) \\
50 \cdot 0(4) \\
16 \cdot 4(61)\end{array}$ & $\begin{array}{l}58 \cdot 3(24) \\
50 \cdot 0(4) \\
24 \cdot 5(94)\end{array}$ & $\begin{array}{l}50 \cdot 0(16) \\
0 \quad(2) \\
10 \cdot 8(74)\end{array}$ & $\begin{array}{l}68 \cdot 6(102) \\
55 \cdot 2(29) \\
23 \cdot 4(458)\end{array}$ \\
\hline
\end{tabular}

Analysis of these results, using the logistic transform of the presence or absence of symptoms as the response variable, confirmed the importance of smoking habits, after adjustment for other possible effects associated with age. A cigarette smoker (at the mean age and with the mean dust exposure) was between two and three times more likely to report chronic cough and phlegm or breathlessness than a comparable non-smoker. Dust exposure was also related,

Table 6 Estimates* of probabilities (\%) of reporting symptoms at the mean age (49) anddust ('xposure $\left(200 \mathrm{ghm}^{-3}\right)$

\begin{tabular}{lll}
\hline & $\begin{array}{l}\text { Cigarette } \\
\text { smokers }\end{array}$ & Non-smokers \\
\hline (a) Chronic cough and phlegm: & & \\
Small rounded opacities & 57 & 23 \\
Small irregular opacities & 52 & 20 \\
No opacities (category 0/0) & 38 & 12 \\
(b) Breathlessness: & 65 & 34 \\
Small rounded opacities & 47 & 20 \\
Small irregular opacities & 31 & 11 \\
\hline No opacities (category 0/0) & 31 & \\
\hline
\end{tabular}

*From logistic regression analyses; see appendix additionally and significantly, to increased chances of reporting the symptoms. The fitted equations suggest that in non-smokers with no small opacities, aged 49, and with negligible dust exposure the prevalence rates of chronic cough and phlegm and of breathlessness would be about $8 \%$ and $5 \%$ respectively. Corresponding estimates for similar miners with the mean dust exposure $\left(200 \mathrm{ghm}^{-3}\right)$ are $12 \%$ and $11 \%$; at $400 \mathrm{ghm}^{-3}$ exposure they are $19 \%$ and $23 \%$. Age did not affect the chances of reporting chronic cough and phlegm in these data but breathlessness was related significantly to increasing age $(\mathrm{p}<0.02)$.

The effects of differences in radiological appearances are indicated in table 6 by adjusted estimates of probabilities of recording the defined symptoms among cigarette smokers and non-smokers. The higher risks of both symptoms in men with small rounded opacities differ significantly from those estimated for miners with no small opacities $(p<0.02$ for chronic cough and phlegm and $\mathrm{p}<10^{-5}$ for breathlessness). The lower excess risks of symptoms in men with small irregular opacities (table 6) could have arisen by chance $(p>0 \cdot 1)$.

Table 7 Mean lung function, age, and dust exposure in various subgroups

\begin{tabular}{|c|c|c|c|c|c|c|c|c|c|c|c|c|c|}
\hline \multirow{2}{*}{$\begin{array}{l}\text { Smoking habit } \\
\text { Appearance of radiograph } \\
\text { No of men }\end{array}$} & & \multicolumn{3}{|c|}{ Cigarette smokers } & \multicolumn{3}{|c|}{ Other smokers } & \multicolumn{3}{|c|}{ Ex-smokers } & \multicolumn{3}{|c|}{ Non-smokers } \\
\hline & & $\begin{array}{l}0 / 0 \\
320\end{array}$ & $\begin{array}{l}S R O \\
67\end{array}$ & $\begin{array}{l}S I O \\
25\end{array}$ & $\begin{array}{l}0 / 0 \\
73\end{array}$ & $\underset{15}{S R O}$ & $\begin{array}{l}S I O \\
4\end{array}$ & $\begin{array}{l}0 / 0 \\
110\end{array}$ & $\underset{28}{S R O}$ & $\underset{6}{S I O}$ & $\begin{array}{l}0 / 0 \\
80\end{array}$ & $\begin{array}{l}S R O \\
20\end{array}$ & $\underset{4}{S I O}$ \\
\hline $\begin{array}{l}\mathrm{FEV}_{1}(\mathrm{ml}) \\
\mathrm{FVC}^{*}(\mathrm{ml}) \\
\mathrm{FEV}_{1} / \mathrm{FVC}^{*}(\%) \\
\text { Age } \\
\text { Dust exposure }\left(\mathrm{ghm}^{-3}\right)\end{array}$ & $\begin{array}{l}\text { Mean } \\
\text { SD } \\
\text { Mean } \\
\text { SD } \\
\text { Mean } \\
\text { SD } \\
\text { Mean } \\
\text { SD } \\
\text { Mean } \\
\text { SD }\end{array}$ & $\begin{array}{c}3031 \\
743 \\
4094 \\
863 \\
73 \cdot 9 \\
8 \cdot 6 \\
47 \\
9 \\
167 \\
99\end{array}$ & $\begin{array}{c}2569 \\
623 \\
3578 \\
733 \\
71 \cdot 7 \\
9 \cdot 2 \\
53 \\
6 \\
328 \\
137\end{array}$ & $\begin{array}{c}2386 \\
781 \\
3454 \\
924 \\
68 \cdot 4 \\
7 \cdot 6 \\
55 \\
7 \\
262 \\
168\end{array}$ & $\begin{array}{c}3079 \\
757 \\
4212 \\
813 \\
72 \cdot 2 \\
8 \cdot 7 \\
50 \\
8 \\
175 \\
93\end{array}$ & $\begin{array}{c}2760 \\
701 \\
3893 \\
853 \\
71 \cdot 0 \\
8.9 \\
55 \\
6 \\
313 \\
110\end{array}$ & $\begin{array}{c}2300 \\
1233 \\
3288 \\
1719 \\
70 \cdot 3 \\
8 \cdot 3 \\
55 \\
7 \\
400 \\
86\end{array}$ & $\begin{array}{c}2991 \\
788 \\
4011 \\
854 \\
73 \cdot 9 \\
11 \cdot 0 \\
50 \\
8 \\
173 \\
111\end{array}$ & $\begin{array}{c}2566 \\
760 \\
3529 \\
879 \\
72 \cdot 4 \\
9 \cdot 0 \\
53 \\
8 \\
297 \\
119\end{array}$ & $\begin{array}{c}2525 \\
393 \\
3658 \\
211 \\
69 \cdot 0 \\
9 \cdot 8 \\
54 \\
3 \\
298 \\
139\end{array}$ & $\begin{array}{c}3169 \\
746 \\
4124 \\
814 \\
76 \cdot 2 \\
9 \cdot 0 \\
45 \\
9 \\
150 \\
99\end{array}$ & $\begin{array}{c}2810 \\
522 \\
3700 \\
655 \\
76 \cdot 5 \\
9 \cdot 2 \\
51 \\
8 \\
320 \\
119\end{array}$ & $\begin{array}{c}2362 \\
932 \\
3250 \\
1258 \\
72 \cdot 1 \\
5 \cdot 4 \\
54 \\
7 \\
276 \\
107\end{array}$ \\
\hline
\end{tabular}

0/0: No small opacities; SRO: small rounded opacities; SIO: small irregular opacities.

* No lung function data were available for five of the 757 miners and there were three unreliable FVC records among those with no small opacities. The mean FVC and FEV 1 /FVC ratios for those with category $0 / 0$ are based therefore on 72 other smokers, 109 ex-smokers, and 79 non-smokers. 
LUNG FUNCTION AND SMALL OPACITIES

Men with small irregular opacities, within each smoking category, were older and had experienced greater dust exposures on average than men with category $0 / 0$. The associations apparent in table 7 between average levels of lung function and averages of three correlated variables (age, dust exposure, pneumoconiosis) were studied by multiple regression. Those analyses included height, weight, and dust exposure as explanatory variables and they allowed for possible variations in the effects of age depending on smoking category. Results, and some further tabulations of the raw data, are recorded in the appendix. The main features of these analyses are illustrated in fig 3 .

The analysis confirmed that both age and exposure to dust were related inversely and independently to
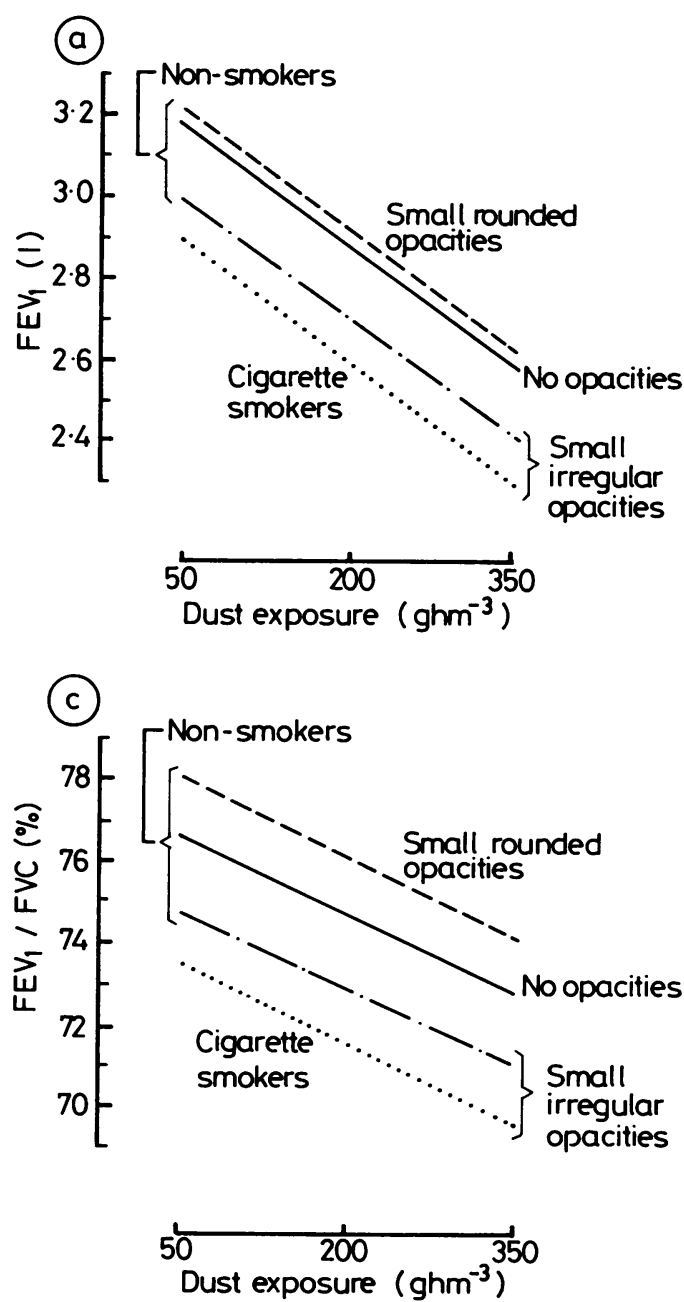

levels of $\mathrm{FEV}_{1}, \mathrm{FVC}$, and to their ratio. After adjustment for variations in age, height, weight, and dust exposure, the presence of small rounded opacities did not affect either the $\mathrm{FEV}_{1}$ or the FVC. Irregularly shaped small opacities, however, were associated with additional decrements in both $\mathrm{FEV}_{1}$ (estimated as $192 \mathrm{ml}$ on average, $\mathrm{p}<0.05$ ) and FVC (a $191 \mathrm{ml} \mathrm{dec}$ rement, $0.05<\mathrm{p}<0.1)$. All the small differences between estimated levels of the $\mathrm{FEV}_{1} / \mathrm{FVC}$ ratio illustrated in fig $3 \mathrm{c}$ are easily attributable to chance except that associated with dust exposure. The latter effect, although statistically significant, amounted to only four percentage units reduction in the ratio per 300 units of exposure.

The lower levels of lung function for cigarette smokers (illustrated in fig 3 by estimates for those
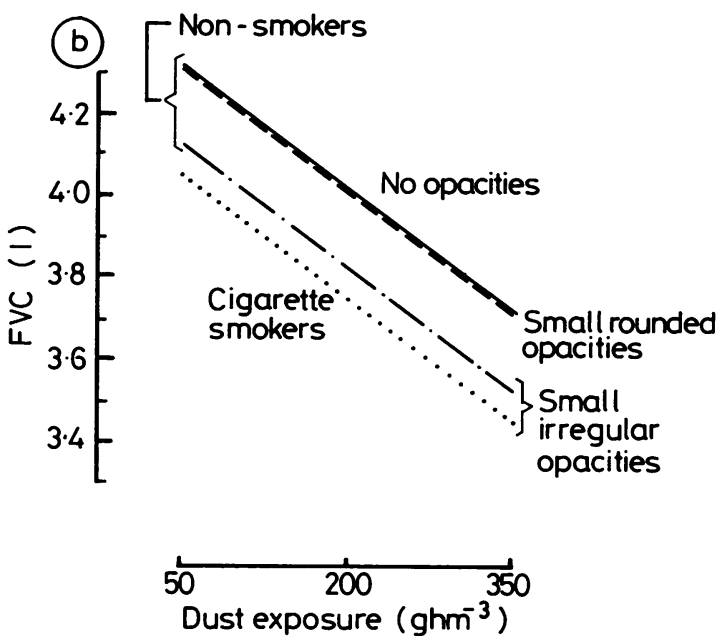

Fig 3 Multiple regression estimates* of relation between lung function ( $\left.F E V_{1}, F V C\right)$ and dust exposure in non-smokers with no pneumoconiosis (-), small rounded opacities (_-) and small irregular opacities (_- -) and in cigarette smokers with small irregular opacities $(\cdots)$. Levels shown refer to a miner at mean age (49) with mean height $(170 \mathrm{~cm})$ and weight $(74 \mathrm{~kg}) .{ }^{*}$ Based on fitted equations recorded in appendix. 
who had small irregular opacities on their radiographs) did not differ significantly from the corresponding estimates for non-smokers. Additional analyses of the data, separately within three age groups, showed a more severe cigarette smoking effect in those aged from 45 to 55 . This amounted to an estimated $252 \mathrm{ml}$ lower level of $\mathrm{FEV}_{1}$ in cigarette smokers than in non-smokers (after allowing for the effects of age, height, weight, dust expostire, and the presence of small opacities) and this difference was statistically significant at the $5 \%$ level. In those aged over 55 the effect of cigarette smoking was less pronounced ( $94 \mathrm{ml}$ lower $\mathrm{FEV}_{1}$ than in non-smokers) and in those aged under 45 it was trivial $(21 \mathrm{ml}$ lower than in non-smokers). These supplementary analyses also confirmed the importance of age, height, and dust exposure within each of the three age groups. The additional functional deficits associated with the presence of small irregular opacities were clear cut only in the two older age groups ( 45 to 55 and those over 55).

These results should be considered in the light of our earlier report. ${ }^{9}$ This showed that the six of us who examined the radiographs all identified small irregular opacities on some of them, and that we were able to do so fairly consistently. Using results from our duplicate sets of film classifications we now confirm that those appearances are related to age and, additionally, to coalmine dust exposure. Moreover, we have shown now that the presence of the small irregularly shaped shadows is associated with a lung function decrement in excess of that attributable directly to dust exposure.

\section{Discussion}

More than 40 years ago researchers in south Wales noted that a small proportion of the coalworkers' chest radiographs that they had studied showed "strands." 13 Those strands were described as thicker than the fine markings characterising the more frequently occurring "reticular" patterns that were considered then to be one of the features distinguishing the appearance of coalworkers' chest films from those seen in silicosis; and the "reticulation" was said to be associated "not infrequently" with some degree of disability. Nevertheless, the experts who attended the ILO's conference on pneumoconiosis in 1950 resolved that classification of radiographic appearances in both silicosis and coalworkers' pneumoconiosis should be restricted to bilateral, discrete "more or less circular" opacities. ${ }^{14}$ It was recommended specifically that the word reticulation, with its pathoanatomical overtones, should never be used to describe radiographic appearances.

But opinions remained divided. A subsequent revision of the ILO classification in 1958 provided for the categorisation of "linear" opacities on a trial basis (and it reintroduced the controversial adjective reticular in the definition of this type of shadow).$^{15}$ It was agreed, however, that the option for classifying linear opacities would not apply to coalminers' films. Since the 1950s therefore radiological diagnosis of coalworkers' simple pneumoconiosis has been based essentially on the presence of the discrete more or less circular-that is, rounded-shadows and this has been the convention used consistently by medical officers responsible for periodic radiological surveys in the British coal industry since 1959 .

During the past 20 years there has been increased interest in the appearances of chest radiographs of people who have been exposed to asbestos dust. This stimulated the International Union Against Cancer, ${ }^{16}$ and then the ILO,${ }^{17}$ to provide for the recognition and classification of small irregular as well as small rounded shadows. The term irregular was to include appearances that would have been classified as "linear" in the earlier (1958) classification, and it was suggested that such shadows may be seen not only on the films of asbestos workers but also in silicosis, mixed dust pneumoconioses, diatomite pneumoconiosis, and "occasionally in coalminers' pneumoconiosis." 17

It was reported soon afterwards that the irregular shapes were not unusual on films of coalminers who had been examined by the pneumoconiosis panels in south Wales, ${ }^{4}$ and their presence was confirmed subsequently in a much larger and more representative group of American coalworkers. ${ }^{6}$ Interest in these observations was heightened by apparent associations between the occurrence of the irregular (as distinct from rounded) shapes, impairments of lung function, ${ }^{467}$ and necropsy findings indicating emphysema. ${ }^{48}$ The small irregular opacities were seen more often among coalminers who had relatively long histories of work underground, ${ }^{56}$ suggesting that their occurrence might be related to dust exposure.

Interpretation of these findings is not straightforward, however, because the small irregular shadows occurred more frequently also in older coalminers, ${ }^{56}$ in those who smoked cigarettes, and in those with bronchitic symptoms. ${ }^{6}$ Moreover, as noted by the ILO,${ }^{17}$ they occur not only on the chest radiographs of coalminers and asbestos workers; low profusion categories have been reported also in polyvinylchloride production workers, ${ }^{18}$ in ex-shale miners, ${ }^{19}$ in female cigarette smokers with no history of occupational exposure to dust, ${ }^{20}$ and the same type of shadows occur commonly in patients with chronic, not necessarily occupational, pulmonary fibrotic diseases. A further complication is that several well 
controlled epidemiological studies testify to persistent and sometimes quite startling differences of opinion between film readers about the shapes of the small shadows that they see. ${ }^{9181921}$ Nevertheless, it seems clear that small irregular opacities may be identified on the chest films of a wide variety of subjects, both dust exposed and non-dust exposed, if the films are classified according to the standard procedures recommended by the ILO.

The 1980 revision of the ILO classification requires that the profusion of any small opacities should be recorded, irrespective of whether they are rounded or irregular. ${ }^{1}$ Application of this rule when classifying coalminers' chest films means that any irregular opacities seen will contribute to the overall profusion category. It is important therefore to know whether, and to what extent, such lesions result from exposure to coalmine dust.

We decided to tackle the problem by seeking answers to four distinct questions (and associated riders). Firstly, do medical officers responsible for the British coal industry's radiological services recognise the presence of small irregular opacities on coalminers' chest radiographs when they use the ILO's 1980 procedures and the associated standard radiographs? Secondly, how reproducible are such nominations on repeated viewings of the same films by the same readers? (And how much variation is there between readers?) Thirdly, are the chances of having irregular opacities relatable directly to coalmine dust exposure? (And if so, how does the exposure-response relation compare with that for small rounded opacities?) Fourthly, are the irregular small opacities associated with respiratory symptoms or impairments of lung function to a greater degree than would be expected by virtue of the miners' ages, body sizes, smoking habits, and exposures to coalmine dust?

When planning the study we took advantage of the fact that the Pneumoconiosis Field Research has generated chest radiographs of many thousands of coalminers from all the British coalfields, ${ }^{2}$ using standardised radiographic techniques, and that these films are accompanied by reliable estimates of cumulative exposures to respirable coalmine dust for each of the individuals concerned. ${ }^{3}$ The availability of data about the same miners' responses to questions on respiratory symptoms and smoking habit, ${ }^{10}$ and on their ventilatory capacity, ${ }^{11}$ afforded a unique opportunity to study the inter-relations of radiological appearances, measured dust exposures (as distinct from surrogates such as years worked underground), symptoms, and respiratory function. The particular set of films selected for the study were from surveys conducted in the early 1970s. This implies that our observations are relevant to conditions in coalmines during the 1950s and 1960s, rather than later. It is important to note also that the sample of men whose films were examined was chosen deliberately to provide a more or less uniform distribution of exposures to dust - so as to maximise the precision of estimates of exposureresponse relations. That choice implies that the proportions of miners with different radiological abnormalities as reported here cannot be regarded as estimates of the prevalence of those conditions among British miners generally.

The answers to the questions that we posed appear to be as follows. Readers who have classified many thousands of coalminers' chest radiographs do identify a small proportion of them as showing predominantly irregular, as distinct from rounded, small opacities when they use the ILO's 1980 conventions. The frequency of these judgements varies between readers, but they are reasonably consistent and reproducible. $^{9}$ Those appearances are related unambiguously to coalmine dust exposures, and additionally to the miners' ages. The exposure specific gradient for irregular shadows, and the average level of profusion, are both lower than the corresponding measures for small rounded opacities. We found that coalminers with any small shadows on their chest radiographs were more likely to have reported chronic cough and phlegm, and breathlessness, than miners with no small shadows. The difference was particularly pronounced for those who had predominantly small rounded opacities, and this result is consistent with an earlier report. ${ }^{10} \mathrm{~A}$ smaller excess of symptoms in those with predominantly small irregular opacities was explicable partly in terms of the men's dust exposures and was not statistically significant. The small irregular opacities, however, were associated with an impairment in ventilatory capacity over and above that attributable to dust exposure as such, and in this respect they differ from small rounded opacities.

The nature of the disturbance in lung function associated with irregular opacities is of interest because this may provide a clue to the underlying pathology. Both the mean $\mathrm{FEV}_{1}$ and the mean FVC were significantly lower in miners with small irregular opacities than in those with category $0 / 0 \mathrm{films}$, after adjustment for differences in ages, dust exposures, and smoking habits. The magnitudes of the effects of $\mathrm{FEV}_{1}$ and on FVC were similar on average and there was only a small (and not statistically significant) decrement in the $\mathrm{FEV}_{1} / \mathrm{FVC}$ ratio. This picture differs from that generally regarded as characterising lung function abnormalities among smokers, who usually have more severe reductions in $\mathrm{FEV}_{1}$ than in FVC. The difference between the patterns might be interpreted as indicating either that irregular opacities signal damage to the lung that causes obstruction at anatomical sites other than those vulnerable to 
tobacco smoke, or that they are a response to more than one type of lesion.

Earlier studies of lung function in coalminers with irregular opacities do not present a consistent picture. One of them showed $\mathrm{FEV}_{1}$ and $\mathrm{FVC}$ reduction patterns associated with small irregular opacities that were similar to those which we found, and there was no change in total lung capacity (TLC). ${ }^{7}$ Another indicated a more substantial effect on the $\mathrm{FEV}_{1} / \mathrm{FVC}$ ratio (but only among smokers) and there was an increase in TLC. ${ }^{6}$ Yet another detected no decrements in either FEV 1 or FVC but did show a reduction in the carbon monoxide transfer factor, ${ }^{22}$ as had been observed also in the two earlier studies. ${ }^{67}$ The variety of these findings supports the idea that irregular opacities may indicate more than one specific pathological lesion, and this would be consistent with the combination of interstitial fibrosis and emphysema described in a small necropsy study of coalminers with irregular opacities. ${ }^{8}$

On the other hand, the parallel reduction in average $F E V_{1}$ and $F V C$ with only small reductions in the $\mathrm{FEV}_{1} / \mathrm{FVC}$ ratio, which we have found to be associated with small irregular opacities, is a similar pattern to that which our analyses attribute to the effect of dust exposure as such, irrespective of the presence of small opacities; and the same pattern has been described as characteristic of coalmine dust exposure in an earlier study. ${ }^{23}$ More detailed descriptions of the functional effects of measured coalmine dust exposures have not yet been published, but studies which appealed to the presence of coalworkers' simple pneumoconiosis (small rounded opacities) as a surrogate for dust exposure have suggested that such exposures are associated with an increase in residual volume ${ }^{24}$ and with frequency dependence of compliance, ${ }^{25}$ implying peripheral airflow obstruction. The evidence to date is not conclusive.

Further studies are in progress of the implications of small irregular opacities on coalminers' chest films in terms of radiological progression, deterioration in pulmonary function, and risks of progressive massive fibrosis. In the meantime, we believe that there is now sufficient evidence to justify taking account of both small irregular as well as small rounded opacities when assessing coalminers' chest radiographs for pneumoconiosis. The latest (1980) version of the ILO classification ${ }^{1}$ provides a convenient and well tested basis for such assessments.

\section{Appendix}

SOME FURTHER DETAILS FROM THE

STATISTICAL ANALYSIS

Interpretations of findings from this study appeal strongly to results from a large number of regression analyses. The following notes and tables provide some further information and they record the estimates of regression coefficients that have been used in the text.

Table 8 Mean $F E V_{1}(\mathrm{ml})$ (and number of men) by age, radiographic appearance, and smoking category

\begin{tabular}{|c|c|c|c|c|c|c|c|c|c|}
\hline & \multicolumn{9}{|l|}{ Age } \\
\hline & $<30$ & $30-34$ & $35-39$ & $40-44$ & $45-49$ & $50-54$ & $55-59$ & $60-64$ & Total \\
\hline \\
\hline $\begin{array}{l}\text { SRO* } \\
\text { SIO }\end{array}$ & & & $\begin{array}{l}4050(1) \\
3850(1)\end{array}$ & $3062(4)$ & $\begin{array}{l}2972(16) \\
2758(6)\end{array}$ & $\begin{array}{l}2343(14) \\
2083(3)\end{array}$ & $\begin{array}{l}2376(25) \\
2344(9)\end{array}$ & $\begin{array}{l}2300(7) \\
1983(6)\end{array}$ & $\begin{array}{l}2569(67) \\
2386(25)\end{array}$ \\
\hline $0 / 0$ & $3600(1)$ & $3705(29)$ & $3807(42)$ & $3252(49)$ & $2837(68)$ & $2854(50)$ & $2631(52)$ & $2317(29)$ & $3031(320)$ \\
\hline \multicolumn{10}{|l|}{ Other smokers: } \\
\hline $\begin{array}{l}\text { SRO } \\
\text { SIO }\end{array}$ & & & $3000(1)$ & $4400(1)$ & & $\begin{array}{l}2400(3) \\
1500(1)\end{array}$ & $2656(8)$ & $\begin{array}{l}2775(2) \\
2100(1)\end{array}$ & $2760(15)$ ㅇ \\
\hline $0 / 0$ & & $3975(4)$ & $3738(4)$ & $3500(10)$ & $3391(11)$ & $2934(16)$ & $2728(20)$ & $2512(8)$ & $3079(73)$ \\
\hline \multicolumn{10}{|l|}{ Ex-smokers: } \\
\hline $\begin{array}{l}\text { SRO } \\
\text { SIO }\end{array}$ & & $4050(1)$ & $3675(2)$ & $2950(2)$ & $2875(2)$ & $\begin{array}{l}2414(7) \\
2467(3)\end{array}$ & $\begin{array}{l}2450(9) \\
2583(3)\end{array}$ & $1970(5)$ & $\begin{array}{l}2566(28) \\
2525(6)\end{array}$ \\
\hline $0 / 0$ & & $3133(3)$ & $3369(13)$ & $3659(16)$ & $3093(21)$ & $2716(19)$ & $2746(24)$ & $2489(14)$ & $2991(110)$ \\
\hline \multicolumn{9}{|l|}{ Non-smokers: } & $2810(20)$ \\
\hline SIO & & & & $\begin{array}{l}3250(3) \\
3100(1)\end{array}$ & & & $1800(2)$ & $2750(1)$ & $2362(4)$ \\
\hline $0 / 0$ & & $3723(11)$ & $3492(13)$ & $3414(18)$ & $3035(13)$ & $2956(8)$ & $2564(11)$ & $2408(6)$ & $3169(80)$ \\
\hline \multicolumn{10}{|l|}{ Total: } \\
\hline $\begin{array}{l}\text { SRO } \\
\text { SIO }\end{array}$ & & $4050(1)$ & $\begin{array}{l}3342(6) \\
3850(1)\end{array}$ & $\begin{array}{l}3230(10) \\
3100(1)\end{array}$ & $\begin{array}{l}2957(22) \\
2950(7)\end{array}$ & $\begin{array}{l}2419(27) \\
2164(7)\end{array}$ & $\begin{array}{l}2452(47) \\
2263(15)\end{array}$ & $\begin{array}{l}2329(117) \\
2094(8)\end{array}$ & $2396(39)$ \\
\hline $0 / 0$ & $3600(1)$ & $3696(47)$ & $3667(72)$ & $3380(93)$ & $2961(113)$ & $2848(93)$ & $2668(107)$ & $2396(57)$ & $3048(583)$ \\
\hline \multicolumn{10}{|c|}{ *0/0: No small opacities; SRO: small rounded opacities; SIO: small irregular opacities. } \\
\hline
\end{tabular}


Table 9 Mean FEV $(\mathrm{ml})$ (and numbers of men) by age, radiographic appearance, and dust exposure

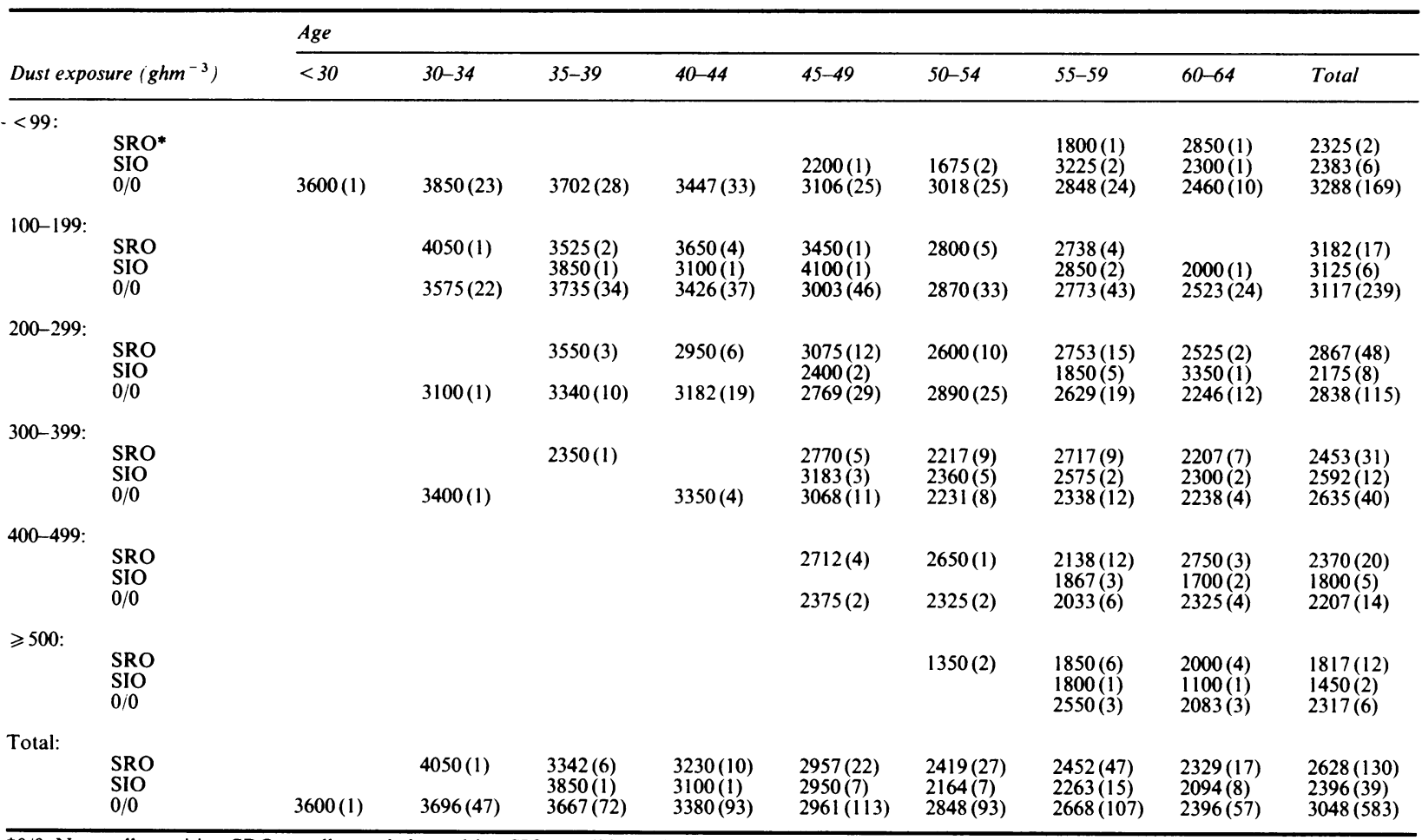

*0/0: No small opacities; SRO: small rounded opacities; SIO: small irregular opacities.

More detailed summaries of the raw data

Tables 8 and 9 provide joint distributions of the numbers of miners studied and their mean FEV 1 levels to five year age groups and concensus radiological categories, by smoking category and by dust exposure ranges respectively.

\section{Small opacities and dust exposure}

The curves shown in fig 2 are based on logistic equations fitted to two subsets of data which both included 587 negative (category $0 / 0$ ) responses (see table 2 ). The expected positive correlation between age and dust exposure was moderate in this particular group of miners $(\mathrm{r}=0.37$ with $716 \mathrm{df}$ for those contributing to the analysis of small rounded opacities (SRO) and $r=0.32$ with $624 \mathrm{df}$ for the analysis of small irregular opacities (SIO)).

The explanatory variables were entered into the equation in the order indicated in table 10.

\section{Respiratory symptoms and small opacities}

The estimates quoted in table 6 are based on logistic equations fitted to two subsets of data, (a) and (b), which both included 396 responses to the question- naire that were not classifiable either as chronic cough and phlegm or as breathlessness. Subset (b) included 116 reports of breathlessness together with chronic cough and phlegm and 76 reports of breathlessness without chronic cough and phlegm. Table 11 records the corresponding regression coefficients and their standard errors.

Lung function and small opacities

Figure 3 illustrates selected features of multiple

Table 10 Regression coefficients (and standard errors) from analyses of the occurrence of small rounded opacities (SRO) and small irregular opacities (SIO)

\begin{tabular}{|c|c|c|}
\hline Response variable & $Y=\operatorname{Logit}(S R O)$ & $Y=\operatorname{Logit}(\mathrm{SIO})$ \\
\hline $\begin{array}{l}\text { Explanatory variables: } \\
\text { Constant (non-smoker) } \\
10 \text { years' age } \\
100 \text { ghm }{ }^{-3} \text { dust exposure } \\
\text { Cigarette smoker } \\
\text { Other smoker } \\
\text { Ex-smoker } \\
\text { Residual df }\end{array}$ & $\begin{array}{r}-4.557(0.771) \\
0.200(0.155) \\
0.975(0.103) \\
-0.297(0.332) \\
-0.349(0.431) \\
-0.097(0.384) \\
712\end{array}$ & $\begin{aligned}-8.22(1.43) \\
0.799(0.257) \\
0.573(0.133) \\
0.344(0.582) \\
-0.175(0.755) \\
-0.216(0.695) \\
620\end{aligned}$ \\
\hline
\end{tabular}


Table 11 Regression coefficients (and standard errors) from analyses of the occurrence of chronic cough and phlegm without breathlessness (CCP without $B$ ) and breathlessness (B)

\begin{tabular}{lrr}
\hline Response variable & $\begin{array}{l}\text { Y = Logit } \\
\text { (CCP without B) }\end{array}$ & $Y=$ Logit (B) \\
Explanatory variables: & & \\
$\quad$ Constant (non-smoker, & $-1.907(0 \cdot 595)$ & $-4 \cdot 379(0.689)$ \\
category 0/0) & $-0 \cdot 116(0 \cdot 11)$ & $0 \cdot 301(0 \cdot 128)$ \\
10 years' age & $1 \cdot 458(0.333)$ & $1 \cdot 280(0.342)$ \\
Cigarette smoker & $0 \cdot 708(0.425)$ & $0 \cdot 701(0.422)$ \\
Other smoker & $0 \cdot 556(0.391)$ & $0 \cdot 856(0.380)$ \\
Ex-smoker & $0 \cdot 257(0.098)$ & $0 \cdot 418(0.094)$ \\
100 ghm ${ }^{-3}$ dust exposure & $0 \cdot 564(0.459)$ & $0 \cdot 652(0.422)$ \\
Small irregular opacities & $0 \cdot 772(0.312)$ & $1 \cdot 417(0 \cdot 275)$ \\
Small rounded opacities & 557 & 580 \\
Residual df & & \\
\hline
\end{tabular}

regression equations (table 12) that were fitted to the available lung function data.

The adequacy of the model as formulated in table 12 was examined by studying residuals and by fitting alternative equations to the data as a whole and to various subsets. In particular, we were alert to possible interactions between cigarette smoking and dust exposure or between cigarette smoking and the presence of either type of small opacity. Neither of these interactions were significant factors in these data. For instance, the dust exposure regression coefficients on $\mathrm{FEV}_{1}$ for cigarette smokers and non-smokers $(-164$ and $-118 \mathrm{ml}$ per 100 units of exposure respectively) did not differ significantly $(t=0 \cdot 7)$. Also, the additional loss in $\mathrm{FEV}_{1}$ attributed to the presence of small irregular opacities was estimated as $197 \mathrm{ml}$ in cigarette smokers and $280 \mathrm{ml}$ in non-smokers. Again, the difference between these estimates was not statistically significant $(t=0 \cdot 3)$.

The text accompanying tables 1 and 2 explains why we restricted the main analyses to three subsets of the data defined from the radiological results. An analysis of $\mathrm{FEV}_{1}$ using all the potentially available data, however, including those from the 138 miners whose radiographs were not interpretable securely, reassured us that their exclusion is not likely to have affected the conclusions about lung function and radiological signs. A regression of $\mathrm{FEV}_{1}$ on the explanatory variables listed in table 12 , supplemented by dummy variables indexing four subgroups of the 138 men previously excluded, gave estimates of coefficients similar to those recorded in table 12. In particular, the average decrement in $\mathrm{FEV}_{1}$ associated with the presence of small irregular opacities was estimated as $219 \mathrm{ml}(\mathrm{t}=2 \cdot 24)$. The standardised mean FEV $_{1}$ levels for three of the newly included subgroups were not distinguishable statistically from levels expected among men with no small opacities. The fourth subgroup, consisting of 13 men with some small opacities, had a significantly lower adjusted mean $\mathrm{FEV}_{1}$ as compared with category $0 / 0$, amounting to a $440 \mathrm{ml}$ decrement $(\mathrm{t}=2 \cdot 59)$. The 13 men concerned correspond to elements $(1,2)$ and $(2,1)$ in the matrix constituting table 1 -that is, miners whose films were judged as showing predominantly rounded shadows at one reading and predominantly irregular shadows at the other.

This research was commissioned and financed by British Coal. We are grateful to our colleagues Drs Anthony Seaton and Colin Soutar for many helpful suggestions.

\section{References}

1 International Labour Organisation. Guidelines for the use of ILO international classification of radiographs of pneumoconioses. (Rev ed 1980.) Geneva: International Labour Office, 1980. (Occupational safety and health series No $22(\operatorname{Rev} 80)$.)

2 Jacobsen M, Rae S, Walton WH, Rogan JM. The relation between pneumoconiosis and dust-exposure in British coal

Table 12 Regression coefficients (and standard errors) from analyses of lung function

\begin{tabular}{|c|c|c|c|}
\hline Response variable & $F E V_{1}(m l)$ & $F V C(m l)$ & $F E V_{1} / F V C(\%)$ \\
\hline $\begin{array}{l}\text { Explanatory variables: } \\
\text { Constant (non-smoker, category } 0 / 0 \text { ) } \\
10 \text { years' age } \\
10 \mathrm{~cm} \text { height } \\
10 \mathrm{~kg} \text { weight } \\
\text { Cigarette smoker } \\
\text { Other smoker } \\
\text { Ex-smoker } \\
\text { Additional } 10 \text { year age effect for: } \\
\text { Cigarette smokers } \\
\text { Other smokers } \\
\text { Ex-smokers } \\
100 \text { ghm }{ }^{-3} \text { dust exposure } \\
\text { Small irregular opacities } \\
\text { Small rounded opacities } \\
\text { Residual df } \\
\text { Residual SD }\end{array}$ & $\begin{array}{r}-1370(650) \\
-317(61) \\
372(36) \\
-9(20) \\
153(323) \\
487(468) \\
49(404) \\
-53(67) \\
-76(94) \\
-22(82) \\
-156(20) \\
-192(95) \\
30(61) \\
739 \\
553\end{array}$ & $\begin{array}{r}-3085(744) \\
-312(69) \\
566(42) \\
-93(23) \\
326(369) \\
1031(541) \\
274(463) \\
-80(77) \\
-149(108) \\
-58(94) \\
-151(22) \\
-191(108) \\
-10(69) \\
736 \\
630\end{array}$ & $\begin{array}{rr}101.3(10.2) \\
-1.9 & (0.9) \\
-1.6 & (0.6) \\
1.6 & (0.3) \\
-1.0 & (5.0) \\
-9.2 & (7.4) \\
-2.6 & (6.3) \\
& \\
-0.1 & (1.0) \\
1.3 & (1.5) \\
0.2 & (1.3) \\
-1.2 & (0.3) \\
-1.9 & (1.5) \\
1.2 & (0.9) \\
736 & \\
8.6 & \end{array}$ \\
\hline
\end{tabular}


mines. In: Walton WH, ed. Inhaled particles III. Old Woking, Surrey: Unwin Bros, 1971:903-19.

3 Hurley JF, Burns J, Copland L, Dodgson M, Jacobsen M. Coalworkers' simple pneumoconiosis and exposure to dust at 10 British coalmines. Br J Ind Med 1982;39:120-7.

- 4 Lyons JP, Ryder RC, Campbell H, Clarke WG, Gough J. Significance of irregular opacities in the radiology of coalworkers' pneumoconiosis. Br J Ind Med 1974;31:36-44.

5 Cockcroft A, Lyons JP, Andersson N, Saunders MJ. Prevalence and relation to underground exposure of radiological irregular opacities in south Wales coal workers with pneumoconiosis. $\mathrm{Br}$ $J$ Ind Med 1983;40:169-72.

6 Amandus HE, Lapp NL, Jacobson G, Reger RB. Significance of irregular small opacities in radiographs of coalminers in the USA. Br J Ind Med 1976;33:13-7.

7 Cockcroft A, Berry G, Cotes JE. Lyons JP. Shape of small opacities and lung function in coalworkers. Thorax 1982;37:765-9.

8 Cockcroft AE, Wagner JC, Seal EME, Lyons JP, Campbell MJ. Irregular opacities in coalworkers' pneumoconiosis-correlation with pulmonary function and pathology. Ann Occup Hyg 1981;26:767-87.

9 Dick JA, Jacobsen M, Gauld S, Pern PO. The significance of irregular opacities in the chest radiographs of British coalminers. In: Proceedings of VI International Pneumoconiosis Conference, Bochum, 1983. Geneva: International Labour Office, 1984:283-99.

10 Rae S, Walker DD, Attfield M. Chronic bronchitis and dust exposure in British coal miners. In: Walton WH, ed. Inhaled particles III. Old Woking, Surrey: Unwin Bros, 1971:883-94.

11 Rogan JA, Attfield MD, Jacobsen M, Rae S, Walker DD, Walton WH. Role of dust in development of chronic bronchitis in British coalminers. Br J Ind Med 1973;30:217-26.

12 Alvey NG, Banfield CF, Baxter CI, et al. GENSTAT: a general statistical program. (Version 4.04 manual.) Harpenden, Herts: Rothamsted Experimental Station, 1977.

13 Hart PD, Aslett EA. Classification of $x$-ray appearances. In: Chronic pulmonary disease in south Wales coalminers-I. London: HMSO, 1942:48-50. (Medical Research Council special report series No 243.)
14 International Labour Organisation. Third international conference of experts on pneumoconiosis. Sydney 1950. Record of Proceedings. Vol 1. Geneva: International Labour Office, 1953:130-3.

15 Meeting of Experts on the International Classification of Radiographs of the Pneumoconioses, Geneva, 1958. Geneva: International Labour Office, 1959. (Occupational safety and health, vol 9 No 2.)

16 International Union against Cancer Committee. UICC/ Cincinnati classification of the radiographic appearances of pneumoconioses. Chest 1970;58:57-67.

17 ILO U/C International classification of radiographs of pneumoconioses 1971. Geneva: International Labour Office, 1972. (Occupational safety and health series 22 (rev).)

18 Soutar CA, Copland LH, Thornley PE, et al. Epidemiological study of respiratory disease in workers exposed to polyvinylchloride dust. Thorax 1980;35:644-52.

19 Seaton A, Louw SJ, Cowie HA. Epidemiologic studies of Scottish oil shale workers: I. Prevalence of skin disease and pneumoconiosis. Am J Ind Med 1986;9:409-21.

20 Carilli AD, Kotzen LM, Fischer MJ. The chest roentgenogram in smoking females. Am Rev Respir Dis 1973;107:133-6.

21 Jacobsen M, Miller BG, Murdoch RM. Experience with the ILO 1980 classification in an epidemiological study of asbestos workers' chest radiographs. In: Proceedings of VI International Pneumoconiosis Conference, Bochum, 1983. Geneva: International Labour Organisation, 1984:868-81.

22 Musk AW, Cotes JE, Bevan C, Campbell MJ. Relationship between type of simple coalworkers' pneumoconiosis and lung function. A nine-year follow-up study of subjects with small rounded opacities. Br J Ind Med 1981;38:313-20.

23 Soutar CA, Hurley JF. Relation between dust exposure and lung function in miners and ex-miners. $\mathrm{Br} J$ Ind Med 1986:43:307-20.

24 Morgan WKC, Burgess DB, Lapp NL, Seaton A, Reger RB. Hyperinflation of the lungs in coal miners. Thorax 1971;26:585-90.

25 Lapp NL, Seaton A. Lung mechanics in coal workers' pneumoconiosis. Ann NY Acad Sci 1972;200:433-54. 